Acta Theriologica 45 (4): 485-490, 2000.

PL ISSN 0001-7051

\title{
"Single-capture" rodents: vagrants or just newly weaned young?
}

\author{
Ewa RAJSKA-JURGIEL and Maria MAZURKIEWICZ
}

\begin{abstract}
Rajska-Jurgiel E. and Mazurkiewicz M. 2000. "Single-capture" rodents: vagrants or just newly weaned young? Acta Theriologica 45: 485-490.

The reliability of the estimation of residency time of the bank vole Clethrionomys glareolus (Schreber, 1780) and the yellow-necked mouse Apodemus flavicollis (Melchior, 1834) in open populations was assessed by halving the 6-week intervals between trapping sessions. The status of "single-capture" individuals was identified to estimate the probability that they are native young rather than adult invaders. We found that the majority of "single-session" individuals constituted true transients that were present in the study plot for a short time only. They were young, immature rodents with a small body mass and a small number of captures. The probability that the "single-session" individuals stay on the plot for a longer time was 0.35 and 0.37 for voles and mice, respectively. These ostensible transients were trap-prone, fully-grown, mature adults, that revealed their presence on the plot already at the beginning of each trapping session. We found that "single-capture" individuals were mainly young, immature rodents that were not retrapped. The probability that the single-capture rodents are mature individuals, with a longer residency time, was 0.10 and 0.18 for voles and mice, respectively.
\end{abstract}

Department of Vertebrate Ecology, Institute of Ecology, Polish Academy of Sciences, Dziekanów Leśny, 05-092 Łomianki, Poland, e-mail: rajska@post.pl

Key-words: Clethrionomys glareolus, Apodemus flavicollis, residency time, single-capture individuals, dispersal

\section{Introduction}

The common occurrence of individuals of small rodents that are caught only once, or only during one trapping session, in extended live trapping programs has been noticed fairly often. With relatively short trapping sessions interspersed at long intervals, this phenomenon is understandable but introduce severe bias into examination of demography and dispersal behavior in open population of rodents. The "transients" may be neighbours, "trap-shy" residents or dispersers moving through the study site (Watts 1970, Flowerdew 1978, Mazurkiewicz and Rajska-Jurgiel 1987, Jones 1990, Tew et al. 1994). As the status of "single-capture" individuals remains unclear, they are usually not included in estimation of population parameters.

Dispersal in rodents is a subject of profound interest (Stenseth and Lidicker 1992). Seasonal and long-term changes in site tenacity can affect population dynamics of woodland rodents in continuous forests (Mazurkiewicz and Rajska- 
-Jurgiel 1998). However, the problem on the status of "single-capture" rodents has been rather neglected, as solving it is difficult due to insufficient information about individuals that arise from insufficient plot size or frequency of trapping.

The effect of plot size on the estimation of residency times of rodents was analyzed elsewhere (Rajska-Jurgiel, in press) but the problem on the status of short-stayers did not disappear with a study grid extension. Trapping programs are compromises between two criteria that are incompatible: (1) we must avoid sampling of "trap-living" populations, (2) we must obtain sufficient numbers of captures of particular individuals. In the study cited above, the interval between trapping sessions was 6 weeks. As this is the time span from conception to weaning of a litter, it allows for recording and marking successive cohorts of young. With this interval, one can also distinguish between (native) juveniles and adult immigrant (Rajska-Jurgiel 1992, 2000).

This paper describes an experiment that explored the consequences of different intervals between censuses on estimation of residency time of the same individuals of the bank vole Clethrionomys glareolus (Schreber, 1780) and the yellow-necked mouse Apodemus flavicollis (Melchior, 1834). This is also an attempt to answer the question: who are the individuals appearing for a short time in the trapping grids? The data come from the main breeding season of moderate density years when disappearance rates of rodents are higher than expected from mortality alone (Mazurkiewicz and Rajska-Jurgiel 1998).

\section{Material and methods}

The study was conducted in the Kampinos National Park, a large forest complex situated near Warsaw $\left(52^{\circ} 20^{\prime} \mathrm{N}, 20^{\circ} 51^{\prime} \mathrm{E}\right)$, in $1988-1989$. A 6 -ha study plot was located in a mosaic of mixed coniferous forest and oak-hornbeam forest (Mazurkiewicz and Rajska-Jurgiel 1998). Live-traps were arranged in a $15 \times 15 \mathrm{~m}$ grid. All data were collected by the capture-recapture method. Trapping was performed five times a year, the midpoints of the trapping sessions being 12 May, 7 June, 2 July, 18 August, and 8 October. A trapping session lasted 7 days. Usually about $95 \%$ of residents are captured in the first 3 days of trapping in island populations (Bujalska and Grüm 1989) or in 4-5 days in open populations (Mazurkiewicz and Rajska-Jurgiel 1987). Traps were checked twice daily. At each capture we noted the rodent number, trap location, sex, reproductive status, body mass and age (based on the body size and pelage color; see Mazurkiewicz and Rajska-Jurgiel 1987, Rajska-Jurgiel 1992).

The interval between trapping sessions in May, June, and July was 3 weeks, thus it was shorter by half than in the study cited above. These data were used to analyze the effect of between-session intervals on estimation of residency time of rodents marked in May and July. The residency time of the same individuals was estimated (1) based on their captures in May and July only, and (2) taking into account information about their captures also in June. All individuals were categorized into those present on the plot over May-July or July-August (residents), and those captured in only one trapping session, either in May or in July ("single-session" individuals or "transients"). In the next step, the transients were grouped into individuals present also in June (ostensible transients or OT) and individuals not captured in June (true transients or TT).

\section{Results}

The material consists of 1255 captures of 232 bank voles and of 530 captures of 149 yellow-necked mice marked in May and July. "Single-session" individuals, 

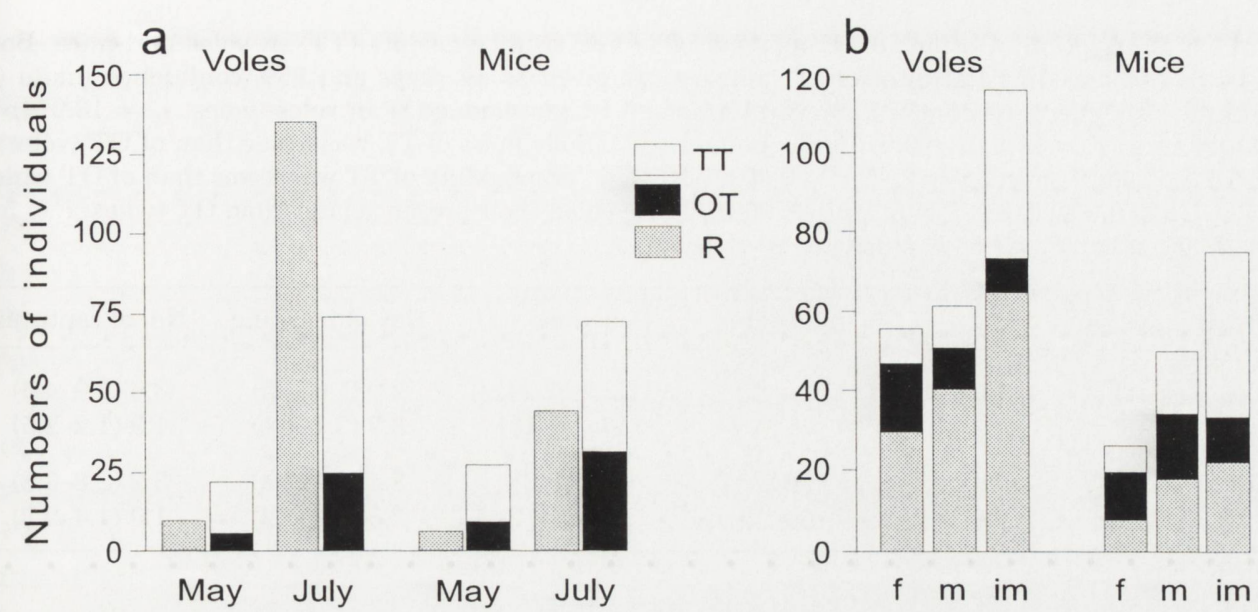

Fig. 1. (a) Numbers of residents (R), ostensible transients (OT) and true transients (TT) among May and July marked rodents. There were proportionally more true transients in mice than in voles (Chi-square test: $\chi^{2}=13.43, p<0.001$ ). (b) Numbers of residents, ostensible transients and true transients among newly marked mature females (f), mature males (m) and immatures (im). There were more true transients among immature recruits than among mature recruits (voles: $\chi^{2}=12.9, p=$ 0.0003 ; mice: $\chi^{2}=11.4, p=0.0007$ ) and more true transients among immature than among mature "single-session" individuals (voles: $\chi^{2}=17.4, p<0.0001$; mice: $\chi^{2}=14.4, p=0.0001$ ).

trapped in only one trapping sessions, accounted for $41 \%$ of the voles and for $66 \%$ of the mice. We found, however, that 35\% of the "single-session" voles and 37\% of the "single-session" mice were in fact present on the plot also in June (Fig. 1a).

Total numbers of residents, ostensible transients and true transients among mature and immature May-July recruits are shown in Fig. 1b. Halving the 6-week interval between trapping sessions, we found that $59 \%$ of mature "single-session" voles and $57 \%$ mature "single-session" mice but only $15 \%$ of immature voles and $20 \%$ of immature mice were the ostensible transients. Thus, $38 \%$ of all immature vole recruits and $55 \%$ of all immature mouse recruits marked in May and July were truly present there only for one trapping session. The respective values for mature recruits were $15 \%$ and $27 \%$.

Ostensible transients (OT) and true transients (TT) differed in many traits (Table 1). TT rodents were predominately immature individuals. The body mass of TT was lower than that of OT. TT individuals revealed their presence on the plot later than did OT. In the first two days, $63 \%$ of OT voles and $60 \%$ of OT mice were captured, but only $26 \%$ of TT voles and $29 \%$ of TT mice. Also the number of captures of TT was lower than that of OT (Table 1).

We found that $48 \%$ of the "single-session" voles and $45 \%$ of the "single session" mice were "single-capture" individuals. It means that they constituted $20 \%$ of all vole recruits and $30 \%$ of all mouse recruits. In total, as many as $76 \%$ of the "single-capture" voles and $71 \%$ of the "single-capture" mice were never retrapped true transients. Among them, $89 \%$ of the voles and $72 \%$ of the mice were immature 
Table 1. Description of ostensible transients (OT) and true transients (TT) in voles and mice. Body mass, day of marking and number of captures are given as averages and 95\% confidence limits (in parentheses). There were more immatures among TT than among OT in voles (voles: $\chi^{2}=13.97, p<$ 0.0001 ; mice: $\chi^{2}=15.3, p<0.0001$, Chi-square test). Body mass of TT was lower than of OT (voles: $F$ $=13.9, p<0.001$; mice: $F=17.4, p=0.001$, ANOVA). Trappability of TT was lower than of OT (voles: $F=5.7, p=0.004$; mice: $F=5.3, p=0.006$ ). TT revealed their presence later than OT (voles: $F=5.8$, $p=0.003$; mice: $F=4.5, p=0.001$ ).

\begin{tabular}{lcccccc}
\hline Species & Class & $n$ & \% immatures & Body mass $(\mathrm{g})$ & Day of marking & No. of captures \\
\hline \multirow{2}{*}{ Voles } & OT & 34 & 24 & $22(20-24)$ & $2.0(1.6-2.5)$ & $3.6(2.9-4.5)$ \\
& TT & 62 & 71 & $17(16-18)$ & $3.7(3.1-4.1)$ & $1.9(1.2-2.5)$ \\
\multirow{2}{*}{ Mice } & OT & 38 & 26 & $26(24-28)$ & $2.4(2.1-2.8)$ & $3.2(2.8-3.8)$ \\
& TT & 61 & 66 & $20(18-22)$ & $3.8(3.2-4.2)$ & $1.9(1.4-2.3)$ \\
\hline
\end{tabular}

young. The body mass of the single-capture individuals that were the true transients and the ostensible transients was $15 \pm 4 \mathrm{~g}$ and $20.5 \pm 6 \mathrm{~g}$, respectively, in voles (ANOVA: $F=8.14, p<0.006)$, and $19.5 \pm 5 \mathrm{~g}$ and $27 \pm 6 \mathrm{~g}$ in mice $(F=9.2$, $p=0.004)$. Only $9 \%$ of all "single-capture" voles and $18 \%$ of all "single-capture" mice were mature individuals, with a longer residency time.

\section{Discussion}

We found that seed-eating mice being hunters rather than croppers were less site-tenacious than folivorous voles (see also Mazurkiewicz and Rajska-Jurgiel 1987, 1998, Rajska-Jurgiel 1992, in press). However, home range shift distances were found to decrease with increasing density in the voles, but not in the mice. At low density, under poor habitat conditions, dispersal distances and emigration/ immigration rates significantly increase (Mazurkiewicz and Rajska-Jurgiel 1998). In both species, observed range lengths increase with time. The lifetime ranges, needed to satisfy all requirements over the life cycle, can be quite large even in such small creatures (Mazurkiewicz and Rajska-Jurgiel 1998, Rajska-Jurgiel 2000, in press).

Halving the time between censuses, we found that most of the "single-session" rodents actually stayed on the study plot for a short time only. The probability that so-called transients stay longer on the plot was higher for mature than immature individuals, and increased with their body mass and number of captures. The majority of "single-session" rodents were, however, true transients. These were young, immature individuals, with a small body mass. Some of them might have died but most of them probably dispersed. Dispersers commonly are maturing young (Watts 1970, Mazurkiewicz and Rajska-Jurgiel 1975, Bujalska and Grüm 1989, 1995, Gliwicz 1989, 1992, Rajska-Jurgiel 1992, Stenseth and Lidicker 1992, Viitala et al. 1994, Plesner Jensen 1996). According to Viitala et al. (1994), ca $50 \%$ of losses from a bank vole population was due to immature dispersal. Disappearance rates of newly marked rodents are usually higher than expected from mortality alone (Mazurkiewicz and Rajska-Jurgiel 1998). 
Some individuals identified as transients in fact stayed in the study area a little longer. They were trap-prone, fully-grown, mature adults, that revealed their presence on the plot at the very beginning of each trapping session. The adult immigrants often appear on trapping plots, especially at low density (Gliwicz 1989, 1992, Brandt 1992, Mazurkiewicz and Rajska-Jurgiel 1998, Rajska-Jurgiel 2000). Also the immigrants disappeared soon from the plot as rodent populations include some vagrants/dispersers that move across the study plots (Rajska-Jurgiel 2000, in press) and little is known about them.

The practical guidelines to distinguish between the two categories of transients were as follow. Mature rodents that were captured at least three times and revealed their presence on days 1-3 of the trapping session, with a body mass of more than $19 \mathrm{~g}$ in voles and more than $23 \mathrm{~g}$ in mice, were found to be ostensible transients. Immature individuals that were captured 1-2 times and revealed their presence on the plot on days 4-7 of the trapping session, with body mass below $19 \mathrm{~g}$ in voles and below $23 \mathrm{~g}$ in mice, were true transients. Both, the true transients and the ostensible transients were dispersers rather than neighbors or visitors.

What was the true status of "single-capture" individuals as found in this paper? A great majority of them were not adult vagrants but immature young. The probability that "single-capture" rodents were mature adults, with a longer residency time was only 0.09 for the voles and 0.18 for the mice. Young, immature rodents as well as all strangers are usually "trap-shy" individuals (Gliwicz 1970, Watts 1970, Andrzejewski and Rajska 1972, Jensen 1975, Rajska-Jurgiel 1976, Smal and Fairley 1982, Brandt 1992), although their body mass does not significantly affect the trappability (Andrzejewski and Rajska 1972). The "trap-shyness" and the later captures of juveniles may be an effect of gradual changes in home ranges and the dependence on mothers and external food resources. Yet, we know that only few of them mature near the natal site (Watts 1970, Mazurkiewicz and Rajska-Jurgiel 1975, Gliwicz 1989, Stenseth and Lidicker 1992, Rajska-Jurgiel 2000).

The same was found with a method of study grid extension (Rajska-Jurgiel, in press). Neighbors or visitors from the surrounding area accounted for a small percentage of single-capture individuals recorded in the trapping grid. Only $12 \%$ of the voles and $14 \%$ of the mice were immigrants/emigrants that moved between the grid and the surrounding at a distance up to $450 \mathrm{~m}$. Even looking from "beyond" the grid, the probability that "single-capture" rodents were immature young, with short time in the grid and the surrounding area, was 0.88 for voles and 0.86 for mice. However, $12 \%$ of the voles and $17 \%$ of the mice were trapped in the same trapping session off the grid, at a distance up to $350 \mathrm{~m}$, when dispersing across the surrounding area (Rajska-Jurgiel, in press). These two papers show that both "single-capture" and "single-sessions" individuals are true transients/dispersers rather than neighbors or invaders. What are the effects of immature dispersal remains to be studied. However, high immigration rates of woodland rodents (Mazurkiewicz and Rajska-Jurgiel 1998) may suggest that the survival cost of dispersal may be less than some other costs of philopatry. 


\section{References}

Andrzejewski R. and Rajska E. 1972. Trappability of bank vole in pitfalls and live traps. Acta Theriologica 17: 41-56.

Brandt C. A. 1992. Social factors in immigration and emigration. [In: Animal dispersal: small mammals as a model. N. C. Stenseth and W. Z. Lidicker Jr, eds]. Chapman and Hall, London: 96-141.

Bujalska G. and Grüm L. 1989. Social organisation of the bank vole (Clethrionomys glareolus, Schreber 1780) and it's consequences: a model. Oecologia 80: 70-81.

Bujalska G. and Grüm L. 1995. Dispersal behavior in female bank voles, Clethrionomys glareolus (Schreber 1780). Polish Ecological Studies 20: 123-129.

Flowerdew J. B. 1978. Residents and transients in wood mouse populations. [In: Population control by social behavior. F. J. Ebling and D. M. Stoddart, eds]. Praeger Publisher, New York: 46-66.

Gliwicz J. 1970. Relation between trappability and age of individuals in a population of the bank vole. Acta Theriologica 15: 15-23.

Gliwicz J. 1989. Individuals and populations of the bank vole in optimal, suboptimal and insular habitats. Journal of Animal Ecology 58: 237-247.

Gliwicz J. 1992. Patterns of dispersal in non-cyclic populations of small rodents. [In: Animal dispersal: small mammals as a model. N. C. Stenseth and W. Z. Lidicker Jr, eds]. Chapman and Hall, London: 147-159.

Jensen T. S. 1975. Trappability of various functional groups of the forest rodents Clethrionomys glareolus and Apodemus flavicollis and its application in density estimation. Oikos 26: 196-204.

Jones E. N. 1990. Effects of forage availability on home range and population density of Microtus pennsylvanicus. Journal of Mammalogy 71: 353-389.

Mazurkiewicz M. and Rajska-Jurgiel E. 1975. Dispersion of bank voles from their place of birth. Acta Theriologica 20: 71-81.

Mazurkiewicz M. and Rajska-Jurgiel E. 1987. Numbers, species composition and residency of a rodent community in forest and field-forest ecotones. Acta Theriologica 32: 413-432.

Mazurkiewicz M. and Rajska-Jurgiel E. 1998. Spatial behaviour and population dynamics of woodland rodents. Acta Theriologica 43: 137-161.

Plesner Jensen S. 1996. Juvenile dispersal in relation to adult densities in wood mice Apodemus sylvaticus. Acta Theriologica 41: 177-186.

Rajska-Jurgiel E. 1976. Interactions between individuals of a population of the bank vole, Clethrionomys glareolus (Schreber, 1780). Ekologia Polska 24: 3-35.

Rajska-Jurgiel E. 1992. Demography of woodland rodents in fragmented habitat. Acta Theriologica 37: 73-90.

Rajska-Jurgiel E. 2000. Breeding dispersal in Clethrionomys glareolus females. Acta Theriologica 45 : 367-376.

Rajska-Jurgiel E. (in press). Movement behavior of woodland rodents: looking from beyond small trapping grids. Acta Theriologica.

Smal C. M. and Fairley J. S. 1982. The dynamics and regulation of small rodent populations in the woodland ecosystems of Killarney, Ireland. Journal of Zoology, London 196: 1-30.

Stenseth N. C. and Lidicker W. Z. Jr (eds) 1992. Animal dispersal: small mammals as a model. Chapman and Hall, London: 1-365.

Tew T. E., Todd I. A. and Macdonal D. W. 1994. The effects of trap spacing on population estimation of small mammals. Journal of Zoology, London 233: 340-344.

Viitala J., Hakkarainen H. and Ylönen H. 1994. Different dispersal in Clethrionomys and Microtus. Annales Zoologici Fennici 31: 411-415.

Watts C. H. S. 1970. Long distance movement of bank voles and wood mice. Journal of Zoology, London 161: 247-256.

Received 14 June 1999, accepted 6 September 2000. 